\title{
PEMROSESAN CITRA DIGITAL UNTUK KLASIFIKASI TANAMAN CABAI MENGGUNAKAN JARINGAN SARAF TIRUAN BACKPROPOGATION
}

\author{
Mochammad Arie Aldiansyah \\ Program Studi Teknik Informatika Fakultas Telematika dan Industri Kreatif Universitas Trilogi Jakarta \\ Jakarta Indonesia
}

\begin{abstract}
Tanaman cabai merupakan salah satu tanaman yang dapat ditanam di Indonesia, tanaman cabai di Indonesia terdapat berbagai macam jenis, dari yang mudah diidentifikasi perbedaan setiap jenisnya seperti cabai merah dan cabai hijau, maupun hingga yang cukup sulit dibedakan jenisnya seperti cabai ceplik, cabai domba, dan cabai rawit. Pemanfaatan pemrosesan citra digital dan sistem jaringan saraf tiruan pada tanaman cabai juga bisa dipergunakan untuk membedakan jenis tanaman cabai sehingga dapat memaksimalkan penggunakan tanaman cabai itu sendiri, karena setiap jenis dari tanaman cabai memiliki sifat dan cita rasa yang berbeda pula yang terdapat pada tanaman cabai tersebut. Pemrosesan citra pada tanaman cabai ini memerlukan input berupa citra buah cabai yang diambil menggunakan kamera digital, lalu citra buah cabai diolah dengan menggunakan Matlab. dan jaringan saraf tiruan. Parameter yang digunakan untuk masukan jaringan saraf tiruan adalah panjang buah cabai, model atau bentuk buah cabai, nilai red, green, blue, variatif warna pada buah cabai dan juga rasa pada buah cabai. Hasilkan output proses citra digitalbuah cabaiadalah menentukan jenis buah cabai secara akurat. Untuk meminimalisir error dalam proses pengolahan citra maka digunakan algoritma backpropation yang dimana menggunakan 3 layer, yaitu input layer, hidden layer, dan output layer.
\end{abstract}

Keywords - Cabai hias ( Capsicum spp.), karakterisasi, citra digital, Matlab, jaringan saraf tiruan, backpropogation.

\section{Pendahuluan}

Tanaman cabai merupakan tumbuhan yang berasal dari anggota genus Capsicum ( Capsicum Annum L. ). Tanaman cabai termasuk kedalam kategori atau suku terong-terongan ( Solanaceae) dan juga merupakan tanaman yang mudah ditanam baik didataran rendah maupun didataran tinggi. Tanaman cabai mengandung berbagai macam kandungan atau senyawa yang baik bagi kesehatan karena pada tanaman cabai terdapat vitamin A, vitamin $\mathrm{C}$, antioksida yang berguna untuk menjaga tubuh dari serangan radikal bebas dan juga minyak atsiri capsaicin yang memberikan kehangatan panas pada tubuh apabila digunakan untuk rempahrempah. Di Indonesia sendiri terdapat beberapa jenis tanaman cabai yang sudah dibudidayakan seperti tanaman cabai merah, tanaman cabai rawit, tanaman cabai keriting, tanaman cabai hijau, tanaman cabai hias, dan masih banyak lagi. Untuk dapat membedakan setiap jenis pada tanaman cabai maka dibutuhkan sebuah teknologi yang mampu membedakan jenis tanaman cabai berdasarkan ciricirinya.

Penerapan teknologi pada tanaman juga sudah banyak diterapkan dalam berbagai macam hal dan berbagai macam bidang, salah satunya pemanfaatan teknologi jaringan saraf tiruan pada tanaman. Jaringan saraf tiruan merupakan hasil perkembangan ilmu dan teknologi yang kini sedang berkembang pesat. Jaringan Saraf Tiruan yang berupa susunan sel-sel saraf tiruan (neuron) dibangun berdasarkan prinsip-prinsip organisasi otak manusia. Agar dapat menerapkan jaringan saraf tiruan untuk membedakan jenis tanaman cabai diperlukan pula sebuah proses pengolahan citra agar sistem dapat membedakan jenis tanaman cabai berdasarkan bentuk dari tanaman cabai tersebut yaitu dengan menggunakan image processing atau pengolahan citra digital. Sehingga dengan menggunakan image processing dan juga jaringan saraf tiruan diharapkan sistem 
mampu membedakan jenis tanaman pada cabai sesuai dari karakterisasi atau ciri khas yang dimiliki oleh jenis tanaman cabai tersebut. Dalam perkembangannya untuk meminimalisir tingkat kesalahan maka akan digunakan metode backpropogation

\section{TinjauAn PUSTaka}

\section{Cabai}

Tanaman cabai merupakan tumbuhan yang berasal dari anggota genus Capsicum ( Capsicum Annum L. ). Tanaman cabai termasuk kedalam kategori atau suku terong-terongan ( Solanaceae) dan juga merupakan tanaman yang mudah ditanam baik didataran rendah maupun didataran tinggi. Tanaman cabai mengandung berbagai macam kandungan atau senyawa yang baik bagi kesehatan karena pada tanaman cabai terdapat vitamin A, vitamin $\mathrm{C}$, dan juga minyak atsiri capsaicin.

\section{Jaringan Saraf Tiruan}

Jaringan saraf tiruan (JST) atau artificial neural network adalah suatu metode komputasi yang meniru sistem jaringan saraf biologis. Metode ini menggunakan elemen perhitungan non-linier dasar atau bisa disebut juga sebagai neuron yang diorganisasikan sebagai jaringan yang saling berhubungan, sehingga mirip dengan jaringan saraf manusia. Jaringan saraf tiruan dibentuk untuk memecahkan suatu masalah tertentu seperti pengenalan pola atau klasifikasi karena proses pembelajaran jaringan saraf tiruan menyerupai otak manusia dalam dua hal, yaitu :

a) Pengetahuan diperoleh jaringan melalui proses belajar.

b) Kekuatan hubungan antar sel syaraf (neuron) yang dikenal sebagai bobot bobot sinaptik digunakan untuk menyimpan pengetahuan.

Jaringan saraf tiruan ditentukan oleh 3 hal :

a) Pola hubungan antar neuron (disebut arsitektur jaringan).

b) Metode untuk menentukan bobot penghubung (disebut metode training/learning).

c) Fungsi aktivasi, yaitu fungsi yang digunakan untuk menentukan keluaran suatu neuron.

Satu sel syaraf terdiri dari tiga bagian, yaitu: fungsi penjumlah (summing function), fungsi aktivasi (activation function), dan keluaran (output). Untuk studi kasus kali ini, jaringan saraf tiruan akan menggunakan metode backpropogation atau perambatan balik. Metode Backpropagation merupakan sebuah metode yang menggunakan algoritma pembelajaran yang terawasi dan biasanya digunakan oleh perceptron dengan banyak lapisan untuk mengubah bobot-bobot yang terhubung dengan neuron yang ada pada lapisan tersembunyi. Algoritma backpropagation menggunakan error output untuk mengubah nilai bobotnya dalam arah mundur. Untuk mendapatkan error ini, tahap perambatan maju (forward propagation) harus dikerjakan terlebih dahulu. Backpropagation dibentuk dengan membuat generalisasi aturan pelatihan dalam model jaringan dengan cara menambahkan layar tersembunyi.Dalam backpropogation ada 2 prosedur yaitu prosedur pelatihan dan prosedur pengujian. Dalam prosedur pelatihan memiliki 2 proses, yaitu proses perambatan maju dan proses perambatan mundur.

1. Perambatan Maju

Tiap unit masukan pada menerima sinyal $x_{i}$ dan menghatarkan tiap unit sinyal ke semua unit lapisan diatasnya ( hidden layer ). Lalu setiap unit yang tersembunyi jumlahkan bobot sinyal masukannya dengan rumus

$$
z_{-} i n_{j}=v o_{j}+\sum_{i=1}^{n} x_{i} v_{i j}
$$

$v_{o j}=$ bias pada unit tersembunyi japlikasikan fungsi aktivitasnya untuk menghitung sinyal keluarannya, $z_{j}=f\left(z_{\_} i n_{j}\right)$ dan kirimkan sinyal ini keseluruh unit pada lapisan diatasnya.

Lalu tiap unit keluaran jumlahkan bobot sinyal masukannya dengan rumus

$$
y_{-} i n_{k}=w_{o k}+\sum_{j=1}^{n} z_{j} w_{j k}
$$

$\boldsymbol{w}_{o k}=$ bias pada unit keluaran $k$ dan aplikasikan fungsi aktivitasnya untuk menghitung sinyal keluarannya $y_{k}=f\left(y_{-} i n_{k}\right)$

2. Perambatan Mundur

Tiap unit keluaran $\left(y_{k}, k=1, \ldots, m\right)$ menerima pola target yang saling berhubungan pada masukan pola pelatihan, hitung kesalahan informasinya, rumusnya ialah

$$
\delta_{k}=\left(t_{k}-y_{k}\right) f^{1}\left(y_{-} i n_{k}\right)
$$

Hitung koreksi bobotnya dengan

$$
\Delta w_{j k}=\propto \delta_{k} z_{j}
$$

Hitung koreki biasnya (digunakan untuk memperbaharui wok nantinya), dan kirimkan $\delta_{k}$ ke unit-unit pada lapisan dibawahnya. 
Lalu, Setiap unit lapisan tersembunyi $\left(z_{j}, j=1, \ldots, p\right)$ jumlahkan hasil perubahan masukannya (dari unitunit lapisan diatasnya) dengan menggunakan rumus

$$
\Delta_{-} i_{j}=\sum_{k=1}^{m} \delta_{k} w_{j k}
$$

kalikan dengan turunan fungsi aktivasinya untuk menghitung informasi kesalahannya,

$$
\delta_{j}=\delta_{-} i n_{j} f^{1}\left(z_{-} i n_{j}\right)
$$

hitung koreksi bobotnya (digunakan untuk memperbaharui $v_{o j}$ nanti).

Lalu dalam prosedur pengujian dapat dilakukan dengan langkah langkah berikut :

Langkah 0 : Inisialisasi bobot

Langkah 1 : Untuk tiap vektor masukan, lakukan langkah 2-4

Langkah 2 : for $i=1, \ldots ., n$ : atur aktivasi unit masukan $x_{j}$

Langkah 3 : for $j=1, \ldots, p$ :

$$
\begin{aligned}
& z_{-} i n_{j}=v o_{j}+\sum_{i=1}^{n} x_{i} v_{i j} \\
& z_{j}=f\left(z_{-} i n_{j}\right)
\end{aligned}
$$

Langkah 4 : for $k=1, \ldots . ., \mathrm{m}$ :

$$
\begin{aligned}
& y_{-} i n_{k}=w_{o k}+\sum_{j=1}^{n} z_{j} w_{j k} \\
& y_{k}=f\left(y_{-} i n_{k}\right)
\end{aligned}
$$

Langkah 5 : Jika $y_{k} \geq 0,5$ maka $y_{k}=1$, else $y_{k}=0$.

\section{METODE PENELITIAN}

Perancangan sistem diawali dengan mungumpulkan data-data terkait tanaman buah cabai, seperti jenis tanaman cabai, ciri khas atau klasifikasi pada jenis tanaman cabai, dan lainnya yang dapat dijadikan sebagai variabel input. Dalam membangun sistem, perlu dilakukan proses pengolahan citra pada tanaman cabai. Proses pengolahan citra bertujuan untuk mengetahui panjang buah cabai, warna pada buah cabai dan juga model bentuk pada buah cabai. Pengolahan citra dimulai dengan melakukan thresholding pada gambar yang dimana tujuan dilakukannya prosesthresholding adalah untuk membedakan antara background dan juga objek citra. Setelah proses thresholding selanjutnya dilakukan perhitungan nilai-nilai yang dijadikan parameter untuk mendapatkan variabel yang digunakan dalam pengukuran input. Pada pengukuran input keanekaragaman warna menggunakan parameter RGB( Red, Green, Blue ) yang diperoleh dari setiap pixel pada citra. Sedangkan untuk mengukur panjang buah cabai dan model bentuk cabai digunakan dengan cara mengubah citra kedalam bentuk hitam dan putih ( greyscale), lalu dilakukan penghitungan banyaknya jumlah pixel berwarna putih pada citra. Prosedur pelacakan pixel yang membatasi obyek dengan latar belakang dilakukan dengan cara membandingkan warna pixel obyek dengan warna latar belakang. Pixel obyek berwarna putih dan pixel latar belakang berwarna hitam, lalu pixel-pixel

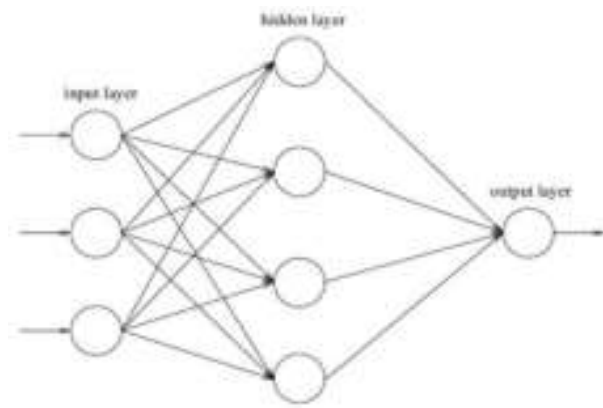

berwarna putih yang berbatasan dengan pixel pixel berwarna hitam merupakan pixel terluar pada citra. Lalu memasukkan beberapa variabel input kedalam artificial neural network (ANN) yang dimana pada jaringan saraf tiruan adanya beberapa layer, seperti layer input, hidden layer dan layer output sebagai cara kerja jaringan saraf tiruan dengan metode perambatan balik itu sendiri ( backpropogation).

Gambar 1. arsitektur jaringan saraf tiruan backpropogation

\section{HASIL DAN PEMBAHASAN}

Pada tahap image processing gambar buah cabai, didapatkan hasil histogram dari gambar buah cabai sebelum proses grayscale seperti gambar 2 dibawah ini, lalu setelah tahap grayscale histogram menjadi seperti gambar 3 .

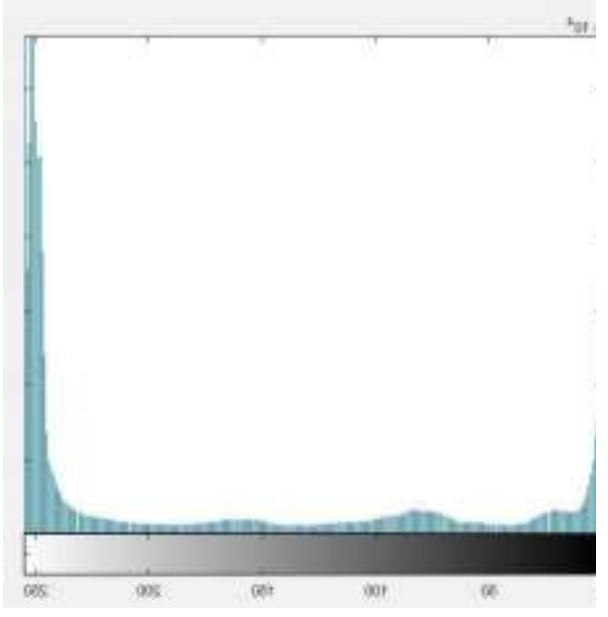


Pemrosesan Citra Digital Untuk Klasifikasi Tanaman Cabai

Gambar 2. Histogram Buah Cabai

Hasil proses grayscale juga dapat dilihat pada gambar 4 dan juga dalam bentuk model hitam dan putih untuk dijadikan sebagai data inputan seperti gambar 5.

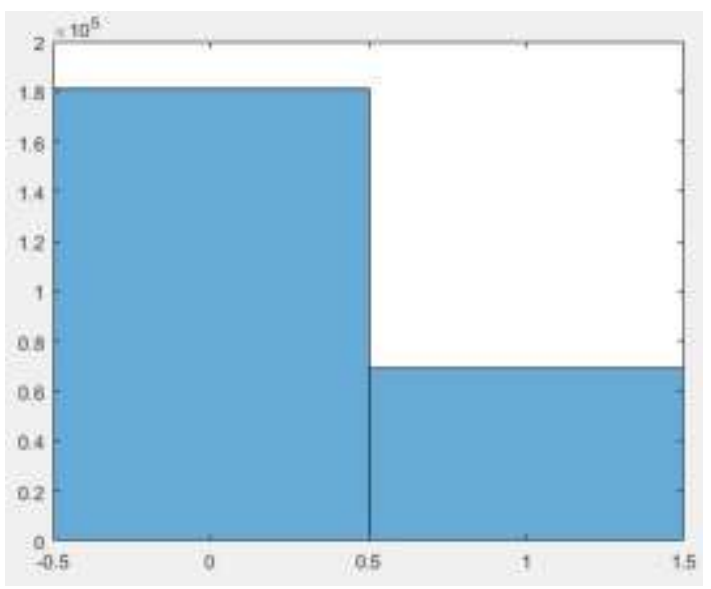

Gambar 3. Histogram Buah Cabai

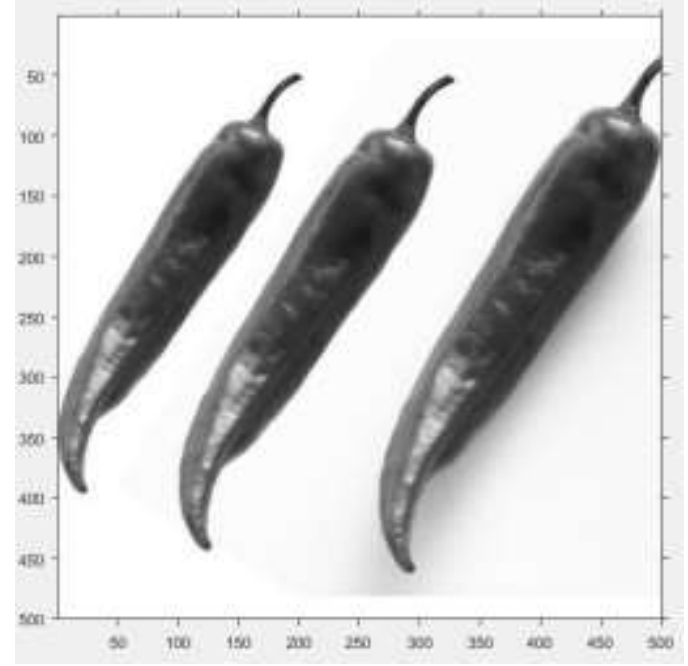

Gambar 4. Hasil Grayscale Buah Cabai

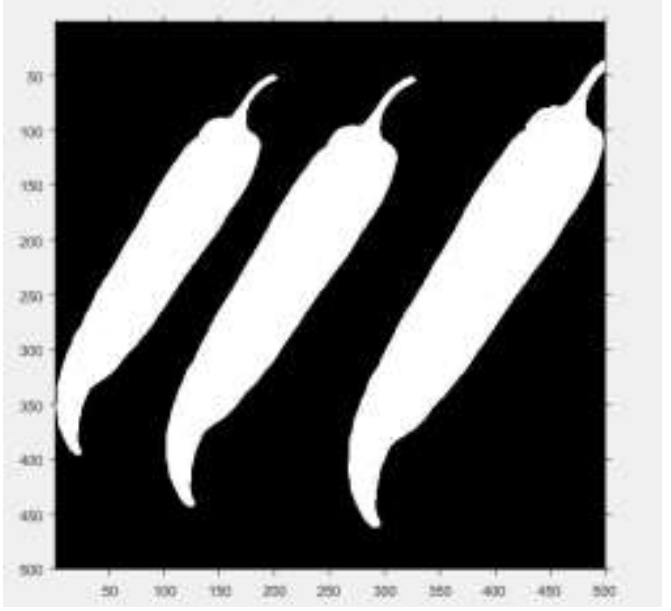

\section{DAFTAR PUSTAKa}

\section{Daftar Pustaka}

[1] Kartika Gunadi, Peter Iksan, 2001. JARINGAN SARAF TIRUAN SEBAGAI ALTERNATIF UNTUK PENYELESAIAN TRAVELLING SALESPERSON PROBLEM. Jurnal Informatika 2, 30-32.

[2] Cahyo, H.D., Pujiyanta, A., 2013. Media Pembelajaran Jaringan Saraf Tiruan Metode Kohonen Berbasis Multimedia. Jurnal Sarjana Teknik Informatika 1, 51-59.

[3] Pujiyanta, A., 2009. Pengenalan Citra Objek Sederhana Dengan Jaringan Saraf Tiruan Metode Perceptron. Jurnal Informatika 3, 268-277.

[4] Laluma, R.H., 2012. Analisis Produktivitas Pegawai Menggunakan Jaringan Saraf Tiruan Propagasi Balik . Jurnal Computech \& Bisnis 6, 69-74.

[5] Purwati, N., 2016. Klasifikasi Status Gizi Balita Berdasarkan Indeks Antropometri $\mathrm{Bb} / \mathrm{U}$ Dan $\mathrm{Bb} / \mathrm{Tb}$ Menggunakan Jaringan Saraf Tiruan. Indonesian Journal on Networking and Security 5, 12-18.

[6] Hidayatno, A., Isnanto, R.R., Kurnia, D., Buana, W., Elektro, J.T., Teknik, F., Diponegoro, U., 2008. IDENTIFIKASI TANDA-TANGAN MENGGUNAKAN JARINGAN SARAF PERAMBATAN-BALIK (BACKPROPAGATION) Achmad. Universitas Diponegoro 100-106.

[7] Suteja, B.R., 2007. Penerapan Jaringan Saraf Tiruan Propagasi Balik Studi Kasus Pengenalan Jenis Kopi. Jurnal Informatika 3, 49-62.

[8] Wiharja, Y.., Harjoko, A., 2014. Pemrosesan Citra Digital untuk Klasifikasi Mutu Buah Pisang Menggunakan Jaringan Saraf Tiruan. Indonesian Journal of Electronics and Instrumentation System 4.

[9] Ramadhani, I., Pratiwi, S.H., Handayani, A.N., 2017. Analisis Jaringan Saraf Tiruan Pengenalan Pola Huruf Hiragana dengan Model Jaringan Perceptron. Jurnal Ilmiah Teknologi Informasi Asia 11, 45-56.

[10] Effendy, N., Imanto, R., Fisika, J.T., Teknik, F., Gadjah, U., Tiruan, J.S., 2008. Deteksi Pornografi Pada Citra Digital Menggunakan Pengolahan Citra dan Jaringan Syaraf Tiruan. Proceedings of National Conference on the Information Technology Research (SRITI).

[11] Kusmaryanto, S., 2014. Jaringan Saraf Tiruan Backpropagation untuk Pengenalan Wajah Metode Ekstraksi Fitur Berbasis Histogram. Jurnal EECCIS Vol. 8, No. 2, $\quad$ Desember 2014 8, 193-198.

[12] Ginting, E.D., 2014. Perancangan Aplikasi Pengenalan Pola Daun Klasifikasi Jenis Tanaman Dengan Pemanfaatan Jaringan Saraf Tiruan Metode Probabilistik. Pelita Informatika Budi Darma.

[13] Musthofa, M.U., Umma, Z.K., Handayani, A.N., 2017. Analisis Jaringan Saraf Tiruan Model Perceptron Pada Pengenalan Pola Pulau di Indonesia. Jurnal Ilmiah Teknologi Informasi Asia 11, 89-100. 
Jurnal Teknologi Informatika dan Terapan Vol. 05, No 01, Januari - Juni 2018 ISSN: 2354-838X

DOI: https://doi.org/10.25047/jtit.v5i1.76

[14] Lesnussa, Y.A., Latuconsina, S., Persulessy, E.R., 2015. Aplikasi Jaringan Saraf Tiruan Backpropagation untuk Memprediksi Prestasi Siswa SMA ( Studi kasus :
Prediksi Prestasi Siswa SMAN 4 Ambon ). Jurnal Matematika Integratif 11, 149-160 
Pemrosesan Citra Digital Untuk Klasifikasi Tanaman Cabai 